OPEN ACCESS

Edited by:

Miguel A. Aon

Johns Hopkins University School

of Medicine, USA

Reviewed by:

Johannes Geiselmann,

University Joseph Fourier, France

Jean Marie François,

Laboratoire d'Ingénierie des

Systèmes Biologiques et des

Procédés UMR-CNRS 5504, France

*Correspondence:

Bing-Zhi L

bzli@tju.edu.cn

tThese authors have contributed equally to this work.

Specialty section:

This article was submitted to Microbial Physiology and Metabolism, a section of the journal

Frontiers in Microbiology

Received: 26 April 2015 Accepted: 08 October 2015

Published: 21 October 2015

Citation:

Qi X, Zha J, Liu G-G, Zhang W, Li B-Z and Yuan Y-J (2015) Heterologous xylose isomerase pathway and evolutionary engineering improve xylose utilization in Saccharomyces cerevisiae. Front. Microbiol. 6:1165.

doi: 10.3389/fmicb.2015.01165

\section{Heterologous xylose isomerase pathway and evolutionary engineering improve xylose utilization in Saccharomyces cerevisiae}

\author{
Xin Qi1,2t, Jian Zha1,2t, Gao-Gang Liu'1,2, Weiwen Zhang ${ }^{1,2}$, Bing-Zhi Lit,2* and \\ Ying-Jin Yuan ${ }^{1,2}$
}

${ }^{1}$ Key Laboratory of Systems Bioengineering, Ministry of Education, Tianjin University, Tianjin, China, ${ }^{2}$ SynBio Research Platform, Collaborative Innovation Center of Chemical Science and Engineering (Tianjin), School of Chemical Engineering and Technology, Tianjin University, Tianjin, China

Xylose utilization is one key issue for the bioconversion of lignocelluloses. It is a promising approach to engineering heterologous pathway for xylose utilization in Saccharomyces cerevisiae. Here, we constructed a xylose-fermenting yeast SyBE001 through combinatorial fine-tuning the expression of XYIA and endogenous XKS1. Additional overexpression of genes RKI1, RPE1, TKL1, and TAL1 in the non-oxidative pentose phosphate pathway (PPP) in SyBE001 increased the xylose consumption rate by 1.19-fold. By repetitive adaptation, the xylose utilization rate was further increased by $\sim 10$-fold in the resultant strain SyBE003. Gene expression analysis identified a variety of genes with significantly changed expression in the PPP, glycolysis and the tricarboxylic acid cycle in SyBE003.

Keywords: synthetic biology, xylose isomerase, XylA, xylose utilization, yeast, evolutionary engineering

\section{INTRODUCTION}

Efficient utilization of xylose is critical for economical cellulosic ethanol production because xylose is the second abundant sugar in lignocellulosic hydrolysates (Li et al., 2010; Qin et al., 2012). Xylose metabolic pathways from natural xylose-fermenting microorganisms have been heterologously expressed in Saccharomyces cerevisiae, which is one of the most promising microbes for cellulosic ethanol production (Zha et al., 2012, 2014). However, the utilization of xylose is much slower than glucose utilization in engineered yeasts (Wang et al., 2014; Shen et al., 2015). Improvement of xylose utilization in engineered yeasts is an urge need for efficient conversion of cellulosic resources.

The xylose reductase/xylitol dehydrogenase (XR/XDH) pathway from fungus, one of the two available ways so far, converts xylose into xylulose catalyzed by NADPH-dependent xylose reductase and $\mathrm{NAD}^{+}$-preferred xylitol dehydrogenase with xylitol as the by-product. The xylose isomerase (XI) pathway converts xylose to xylulose by XI encoded by the gene XylA. In both pathways, xylulose is then channeled into the glycolytic pathway through the non-oxidative pentose phosphate pathway (PPP) to produce ethanol under anaerobic conditions. Several approaches have been applied to optimize the XR/XDH pathway to reduce xylitol production and increase ethanol yield, including protein engineering of the cofactor preference of XR or XDH 
for cofactor recycling, overexpression of the genes in the PPP, and heterologous expression of xylose-specific transporters (Jeppsson et al., 2006; Karhumaa et al., 2007a; Matsushika et al., 2008; Petschacher and Nidetzky, 2008; Bengtsson et al., 2009; Runquist et al., 2009). As an alternative, the XI pathway bypasses the cofactor imbalance and can achieve a much higher ethanol yield close to the theoretical value (Kuyper et al., 2003; Brat et al., 2009; Ha et al., 2011; Lee et al., 2014). However, the overall xylose utilization rate by the XI pathway in yeast is notably lower than that by the XR/XDH pathway, and so efforts are required to increase the xylose utilization rate by this pathway (Kuyper et al., 2003; Chu and Lee, 2007; Karhumaa et al., 2007b; Brat and Boles, 2013; Lee et al., 2014).

Rational metabolic modifications to accelerate xylose uptake and metabolism were employed in recombinant S. cerevisiae expressing the XI pathway (Kuyper et al., 2005a; Lee et al., 2012; Zhou et al., 2012; Nijland et al., 2014; Wang et al., 2015). (i) One or all genes encoding the enzymes in the non-oxidative PPP were over-expressed in S. cerevisiae to increase the flux toward the glycolytic pathway; (ii) XKS1 encoding xylulose kinase responsible for phosphorylation of xylulose was over-expressed to improve xylose fermentation; (iii) Directed evolution of a XI was conducted to accelerate xylose utilization; and (iv) Heterologous xylose-specific transporters were over-expressed to enhance xylose transport. Efficient xylose utilization was achieved in the strain RWB217 by overexpression of XylA, XKS1 and the four genes of RPE1, RKI1, TAL1, and TKL1 in the PPP together with deletion of GRE3 (Kuyper et al., 2005a). However, these modifications did not visibly improve xylose utilization in other host yeasts for unknown reasons (Karhumaa et al., 2007b; Zhou et al., 2012). Thus, alternative approaches need to be introduced to improve xylose utilization in recombinant S. cerevisiae.

Evolutionary engineering was an efficient approach to improving the utilization of non-favored carbon sources such as arabinose and galactose in S. cerevisiae (Wisselink et al., 2010; Hong et al., 2011; Scalcinati et al., 2012; Demeke et al., 2015). Similarly, such a strategy has been successfully applied to evolve the XI pathway for accelerated xylose fermentation (Kuyper et al., 2005b; Zhou et al., 2012; Lee et al., 2014).

In this study, a combinatorial design was used to modulate the expression of XylA from fungus Piromyces and endogenous XKS1 in $S$. cerevisiae. The rational engineering for the non-oxidative PPP and evolutionary engineering resulted in an efficient xyloseutilizing strain.

\section{MATERIALS AND METHODS}

\section{Strains and Media}

Escherichia coli DH5 $\alpha$ was used for plasmid construction in this study and was grown in Luria-Bertani medium with $100 \mathrm{mg} / \mathrm{L}$ ampicillin. Yeast strains used in the study are listed in Table $\mathbf{1 .}$ YNB medium with $20 \mathrm{~g} / \mathrm{L}$ glucose was used in the construction of recombinant yeasts (Zha et al., 2013). Agar plates were prepared by the addition of $20 \mathrm{~g} / \mathrm{L}$ agar. Adaptive evolution was performed in YNB medium with $20 \mathrm{~g} / \mathrm{L}$ xylose. The fermentation was conducted in YPX medium $(10 \mathrm{~g} / \mathrm{L}$ yeast extract, $20 \mathrm{~g} / \mathrm{L}$
TABLE 1 | The strains and plasmids used in this study.

\begin{tabular}{|c|c|c|}
\hline Strain & Genotype & Sources \\
\hline L2612 & MATalpha,leu2,ura3, trp1 & Jin et al., 2003 \\
\hline SyBE001 & $\begin{array}{l}\text { L2612,ura3::[TDH1p-XKS1, } \\
\text { pRS425-TDH3p- XyIA] }\end{array}$ & This study \\
\hline SyBE002 & $\begin{array}{l}\text { SyBE001, AUR1:: } \\
\text { [TDH1p-RPE1,PGK1p-TAL1], trp1:: } \\
\text { [PGK1p-RKI1,TDH3p-TKL1] }\end{array}$ & This study \\
\hline SyBE003 & Evolved from SyBE002 & This study \\
\hline $\mathrm{tk} \mid 2 \Delta$ & Yeast knock-out strain & Open biosystems \\
\hline SyBE002-TKL2 $\Delta$ & SyBE002, tkl2::KanMX & This study \\
\hline \multicolumn{3}{|l|}{ Plasmid } \\
\hline pTDH1XK & Ylplac211, TDH1p-XKS1 & This study \\
\hline pTDH3XK & Ylplac211, TDH3p-XKS1 & This study \\
\hline pPGK1XK & Ylplac211, PGK1p-XKS1 & This study \\
\hline pTDH3XI & pRS425, TDH3p-XyIA (Piromyces) & This study \\
\hline $\mathrm{pHXK2XI}$ & pRS425, HXK2p-XyIA (Piromyces) & This study \\
\hline pPGK1XI & pRS425, PGK1p-XyIA (Piromyces) & This study \\
\hline pAUR101-RPE1-TAL1 & $\begin{array}{l}\text { PAUR101,TDH1p-RPE1-PGK1t, } \\
\text { PGK1p-TAL1-PGK1t }\end{array}$ & This study \\
\hline pRS304-RKI1-TKL1 & $\begin{array}{l}\text { pRS304, PGK1p-RKI1-PGK1t, } \\
\text { TDH3p-TKL1-PGK1t }\end{array}$ & This study \\
\hline
\end{tabular}

peptone, and $20 \mathrm{~g} / \mathrm{L}$ or $40 \mathrm{~g} / \mathrm{L}$ xylose) or YPGX medium (10 g/L yeast extract, $20 \mathrm{~g} / \mathrm{L}$ peptone, $20 \mathrm{~g} / \mathrm{L}$ glucose, and $20 \mathrm{~g} / \mathrm{L}$ xylose).

\section{Plasmid Construction and Transformation Plasmid Construction}

Gene XylA from Piromyces sp. E2 (ATCC 76762) was optimized according to codon preference of $S$. cerevisiae. The synthesized XylA (Supplementary Table S1) was inserted into plasmid pRS425, followed by the insertion of the promoters TDH3p, HXK2p, or PGK1p to form the plasmids pTDH3XI, pHXK2XI, and PPGK1XI, respectively.

To construct the XKS1 cassette, the XKS1 and PGK1 terminator were amplified from the genomic DNA of strain L2612, respectively, and assembled by fusion PCR. The fused fragment was then inserted into plasmid YIplac211. Promoters TDH1p, TDH3p, or PGK1p were inserted in front of XKS1 gene to form three XKS1 cassettes, resulting in plasmids pTDH1XK, pTDH3XK, and pPGK1XK, respectively.

The modules for overexpression of RPE1, RKI1, TAL1, and TKL1 were constructed as follows. The individual expression cassettes, namely TDH1p-RPE1-PGK1t, PGK1pTAL1-PGK1t, PGK1p-RKI1-PGK1t, and TDH3p-TKL1-PGK1t, were obtained by fusion PCR of genomic DNA of yeast L2612. The expression cassettes TDH1p-RPE1-PGK1t and PGK1p-TAL1-PGK1t were then combined together using fusion PCR and inserted into plasmid pAUR101 (Takara Bio, Kyoto, Japan), creating plasmid pAUR101-RPE1-TAL1. Cassettes PGK1p-RKI1-PGK1t and TDH3p-TKL1-PGK1t were assembled and cloned into plasmid pRS304, generating plasmid pRS304-RKI1-TKL1. 
To knockout gene TKL2 in SyBE002, the TKL2 knockout box was amplified from the genomic DNA of the strain $\mathrm{tkl} 2 \Delta$ from the strain collection of single-gene deletion (Open Biosystems, Huntsville, Ala, USA). The constructed knockout DNA fragment was used directly for transformation into SyBE002.

All the primers used in this study were listed in Supplementary Table S2.

\section{Transformation}

The transformants of plasmids pTDH3XI, pHXK2XI, pPGK1XI, pTDH1XK, pTDH3XK, pPGK1XK, and pRS304-RKI1-TKL1 were selected in YNB medium with $20 \mathrm{~g} / \mathrm{L}$ glucose lacking specific amino acids. Integration of pAUR101-RPE1-TAL1 was performed in YNB plate supplemented with $0.5 \mathrm{mg} / \mathrm{L}$ Aureobasidin A (Takara Bio, Kyoto, Japan). The TKL2-knockout strain was selected on YNB plate with $200 \mathrm{mg} / \mathrm{L}$ G418 (Merck, Darmstadt, Germany). All the transformation was conducted according to the standard procedures (Gietz et al., 1995).

\section{Adaptive Evolution on Xylose}

The evolution was carried out in $50 \mathrm{~mL}$ YNB medium with $20 \mathrm{~g} / \mathrm{L}$ xylose in $250 \mathrm{~mL}$ flasks at $30^{\circ} \mathrm{C}$ and $150 \mathrm{rpm}$ under oxygen-limited conditions. For each adaptation cycle, growth was initiated with the cell density of $0.2\left(\mathrm{OD}_{600}\right)$. Further evolution cycles were repeated with the identical conditions and ceased until the constant cell density. After the evolution of about 40 transfers in 75 days, cells from the shaking flasks were streaked on YNB plates with $20 \mathrm{~g} / \mathrm{L}$ xylose for isolation of a single colony. Twenty colonies with the biggest sizes were chosen for additional analysis. The selected colonies were first cultivated in YNB medium containing $20 \mathrm{~g} / \mathrm{L}$ glucose for 2 days, and then 100$\mu \mathrm{L}$ culture was taken and inoculated into 3-mL YNB medium containing $20 \mathrm{~g} / \mathrm{L}$ xylose in rubber-sealed 15-ml culture tubes and cultivated at $30^{\circ} \mathrm{C}$ and $150 \mathrm{rpm}$. The cell density and metabolites were analyzed after $72 \mathrm{~h}$.

\section{Anaerobic Fermentation}

Yeast seeds were cultivated in YNB medium with $20 \mathrm{~g} / \mathrm{L}$ glucose at $30^{\circ} \mathrm{C}$ and $200 \mathrm{rpm}$ and inoculated into fresh media when cells reached mid-log phase. Anaerobic fermentation was performed in $100 \mathrm{~mL}$ of YPX or YPGX in $250-\mathrm{mL}$ flasks sealed by a rubber stopper with a needle to release $\mathrm{CO}_{2}$ produced during fermentation. Flasks were incubated in a rotary shaker (Honor, Tianjin, China) with shaking $(150 \mathrm{rpm})$ at $30^{\circ} \mathrm{C}$. Initial cell densities were 1.0 of $\mathrm{OD}_{600}$ for the fermentation with $20 \mathrm{~g} / \mathrm{L}$ xylose, and 2.0 of $\mathrm{OD}_{600}$ was used for other fermentation. Cell density was monitored by measuring the $\mathrm{OD}_{600}$ using a 756 spectrophotometer (Kanasi, Tianjin, China). The experiments were repeated twice independently.

\section{Analysis of Sugars and Fermentation Products}

Sugars and fermentation products were analyzed using an HPLC system consisting of a Waters 1515 pump (Milford, MA, USA) and a Waters 2414 refractive index detector. The substances were separated on an Aminex HPX-87H carbohydrate analysis column
(Bio-Rad, Hercules, CA, USA) at $65^{\circ} \mathrm{C}$ using $5 \mathrm{mM}$ sulphuric acid as the mobile phase with a flow rate of $0.6 \mathrm{~mL} / \mathrm{min}$.

\section{Transcriptional Analysis by Quantitative RT-PCR}

After anaerobic growth on $20 \mathrm{~g} / \mathrm{L}$ xylose for $18 \mathrm{~h}$, the cells were harvested by centrifugation $(4,000 \mathrm{rpm})$ for $5 \mathrm{~min}$ at $4^{\circ} \mathrm{C}$, followed by two washes with ice-cold water. Then cells were stored in liquid nitrogen before use. Total RNA was extracted by Mini RNA dropout kit (Tiangen, Beijing, China). RNA integrity and quality were verified by RNA electrophoresis and NanoDrop1000 (Thermo Scientific, Wilmington, DE, USA). Totally $1 \mu \mathrm{g}$ of RNA was used for each reverse transcription with the Reverse Transcription Kit (Tiangen, Beijing, China). Transcription was performed for $1 \mathrm{~h}$ at $37^{\circ} \mathrm{C}$. The quantitative measurement was carried out using RealMaster Mix Kit (Tiangen, Beijing, China). For each reaction, a total of $20 \mu \mathrm{L}$ was used consisting of $9 \mu \mathrm{L}$ RealMaster Mix buffer, $0.5 \mu \mathrm{L}$ each of forward and reverse primer (10 $\mu \mathrm{M}$ each), $0.5 \mu \mathrm{L}$ cDNA template, and $9.5 \mu \mathrm{L}$ ddH $_{2} \mathrm{O}$. The primers (Supplementary Table S3) were designed according to the sequences from Saccharomyces Genome Database (http:// www.yeastgenome.org). Quantitative RT-PCR was run in an ABI7300 Thermo cycler and the conditions employed were as follows: $95^{\circ} \mathrm{C}$ for $2 \mathrm{~min} ; 94^{\circ} \mathrm{C}$ for $15 \mathrm{~s}, 60^{\circ} \mathrm{C}$ for $30 \mathrm{~s}$, and $72^{\circ} \mathrm{C}$ for $40 \mathrm{~s}$ (40 cycles). Three biological replicates were performed for each gene. The threshold cycle value $(\mathrm{Ct})$ for each sample was determined using the ABI7300 software. The data was normalized using the gene ACT1 as the internal standard and analyzed according to the $2^{-\Delta \Delta C T}$ method (Schmittgen and Livak, 2008). $\Delta$ CT was obtained by subtracting the $\mathrm{Ct}$ values of ACT1 from the Ct values of the gene of interest. $\Delta \Delta \mathrm{CT}$ was then calculated by subtracting mean $\triangle \mathrm{CT}$ of the samples in SyBE002 from mean $\triangle \mathrm{CT}$ of samples in SyBE003. Fold changes of gene expression were calculated by the equation of $2^{-\Delta \Delta C T}$.

\section{Statistical Analysis}

Student's $t$-test was introduced to statistically analyze the data using statistical function tools of Microsoft Excel 2010. Fisher's exact test and Pearson's $\chi^{2}$ test were applied to determine the significant association between the expression levels in SyBE002 and those in SyBE003. All tests of statistical significance were two sided. $P<0.05$ were considered statistically significant.

\section{RESULTS}

\section{Genetic Construction of Xylose-fermenting Yeasts Expressing the Xylose Isomerase Pathway}

The enzyme products of $X y l A$ and XKS1 catalyze the formation of 5-phosphate-xylulose that was metabolized by the following non-oxidative PPP (Jin et al., 2003; Lonn et al., 2003). Balancing the expression of $X y l A$ and $X K S 1$ can be a way to optimize xylose metabolic pathway and improve xylose utilization. We 
evaluated the effects of different promoters on balancing the expression of XylA and XKS1. The promoters with different transcriptional strengths were applied to tune the expression of $X y l A$ and XKS1. Promoters TDH3p, HXK2p, and PGK1p were applied to express $X y l A$ in a multicopy plasmid pRS425 (Lu and Jeffries, 2007). Promoters TDH1p, TDH3p, and PGK1p were used to control the expression of XKS1. This strategy generated nine recombinant strains with different expression levels of $X y l A$ and XKS1 (Figure 1).

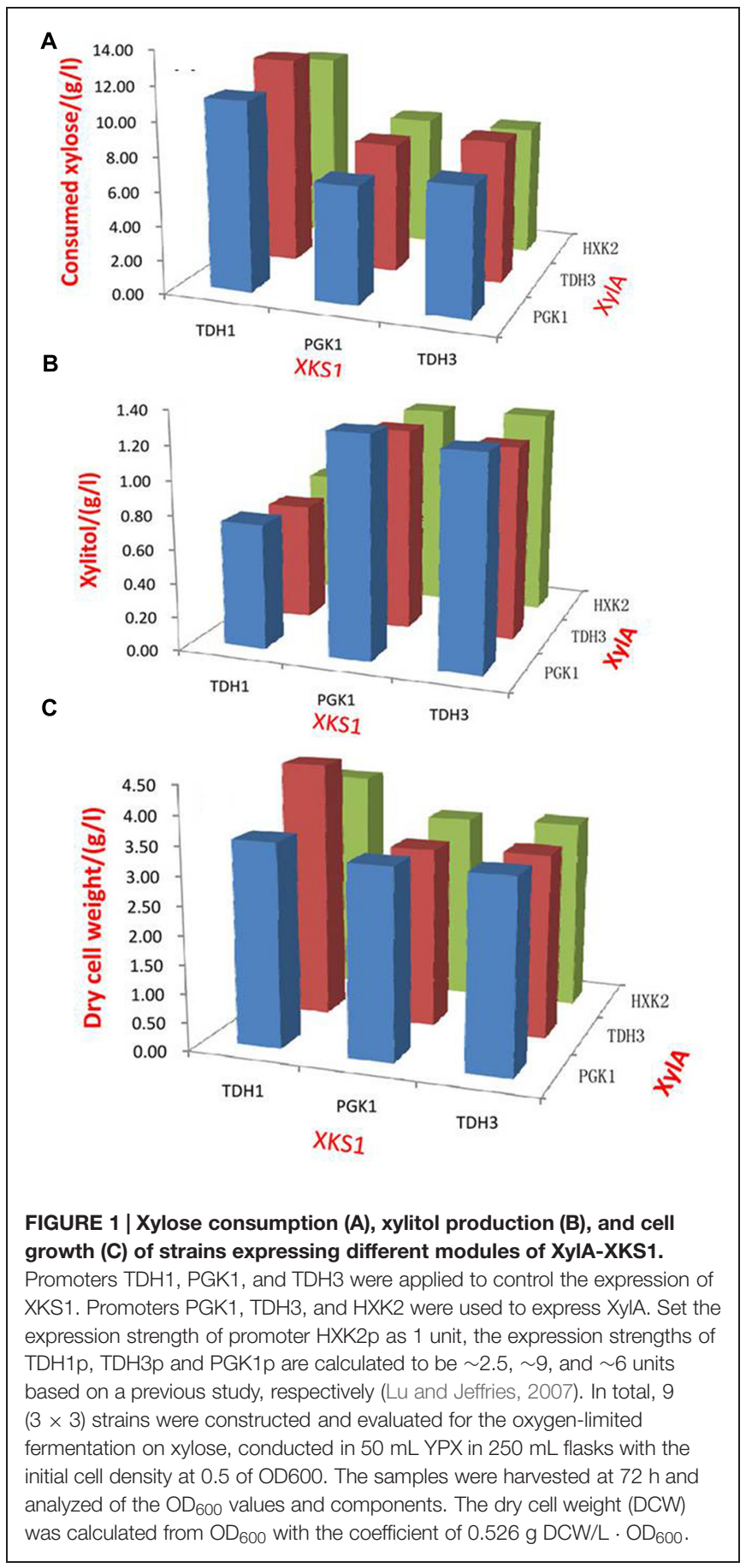

These strains were then comparatively characterized in terms of cell growth, xylose consumption, and xylitol production under oxygen-limited conditions (Figure 1, Supplementary Table S4). The strains with XKS1 under the control of TDH1p showed higher abilities of xylose utilization than those with XKS1 controlled by TDH $3 p$ or PGK1p (Figure 1A). Xylitol production in this group was also much lower than other two groups (Figure 1B). In addition, the cell densities of the cultures were highest in the strains with XKS1 controlled by TDH1p (Figure 1C).

Expression of $X y l A$ had little effect on xylose utilization. When XKS1 was expressed by TDH1 promoter, the strain with XylA controlled by TDH3p, named SyBE001, showed a slightly higher xylose utilization rate and cell density (Figures 1A,C). The xylose consumption rate of SyBE001 was 8.9\%-79.4\% higher than other eight strains (Figure 1A). Thus, we genetically constructed an optimal recombinant $S$. cerevisiae through fine-tuning the expression of $X y l A$ and $X K S 1$.

In the strain SyBE001, the xylose consumption rate was $0.037 \mathrm{~g} / \mathrm{L} / \mathrm{h}$. The ethanol yield and xylitol yield was 0.28 and $0.19 \mathrm{~g} / \mathrm{g}$, respectively. This might be ascribed to the limited flux through the non-oxidative PPP. Enzymes of the non-oxidative PPP are considered to be rate-limiting in xylose metabolism (Karhumaa et al., 2005; Kuyper et al., 2005a; Chu and Lee, 2007). To eliminate these bottlenecks, we over-expressed genes RPE1, RKI1, TAL1, and TKL1 in SyBE001, resulting in strain SyBE002. As shown in Supplementary Figure S1, the expression of the genes was enhanced by 40-134-fold in SyBE002. The fermentation performances of SyBE001 and SyBE002 were also compared to examine the roles of RPE1, RKI1, TAL1, and TKL1 (Figure 2). Compared with strain SyBE001, the xylose consumption rate of SyBE002 increased by 1.19-fold and the ethanol production was enhanced by 1.51 -fold accordingly. Meanwhile, xylitol yield and glycerol yield decreased by $21 \%$ and $43 \%$, respectively. The results demonstrated that overexpression of genes in the non-oxidative PPP could significantly improve xylose fermentation. However, the resultant strain SyBE002 consumed xylose still at a low rate, and therefore further modification is needed to achieve rapid ethanol production from xylose.

\section{Evolutionary Engineering of SyBE002 on Xylose}

To accelerate xylose metabolism in SyBE002, evolutionary engineering was applied. After a 75-day evolution conducted under oxygen-limited conditions, the candidate colonies were selected based on colony sizes as reported before (Du et al., 2012; Kim et al., 2013). Twenty biggest colonies were picked and evaluated in terms of xylose consumption, and the colony exhibiting the highest xylose consumption rate was designated as SyBE003 and investigated further.

\section{Fermentation of SyBE002 and SyBE003 on Xylose}

To compare their abilities to produce ethanol from xylose, the anaerobic fermentation of SyBE002 and SyBE003 was first carried out on $20 \mathrm{~g} / \mathrm{L}$ xylose (Figure 3). During the first $36 \mathrm{~h}$, 


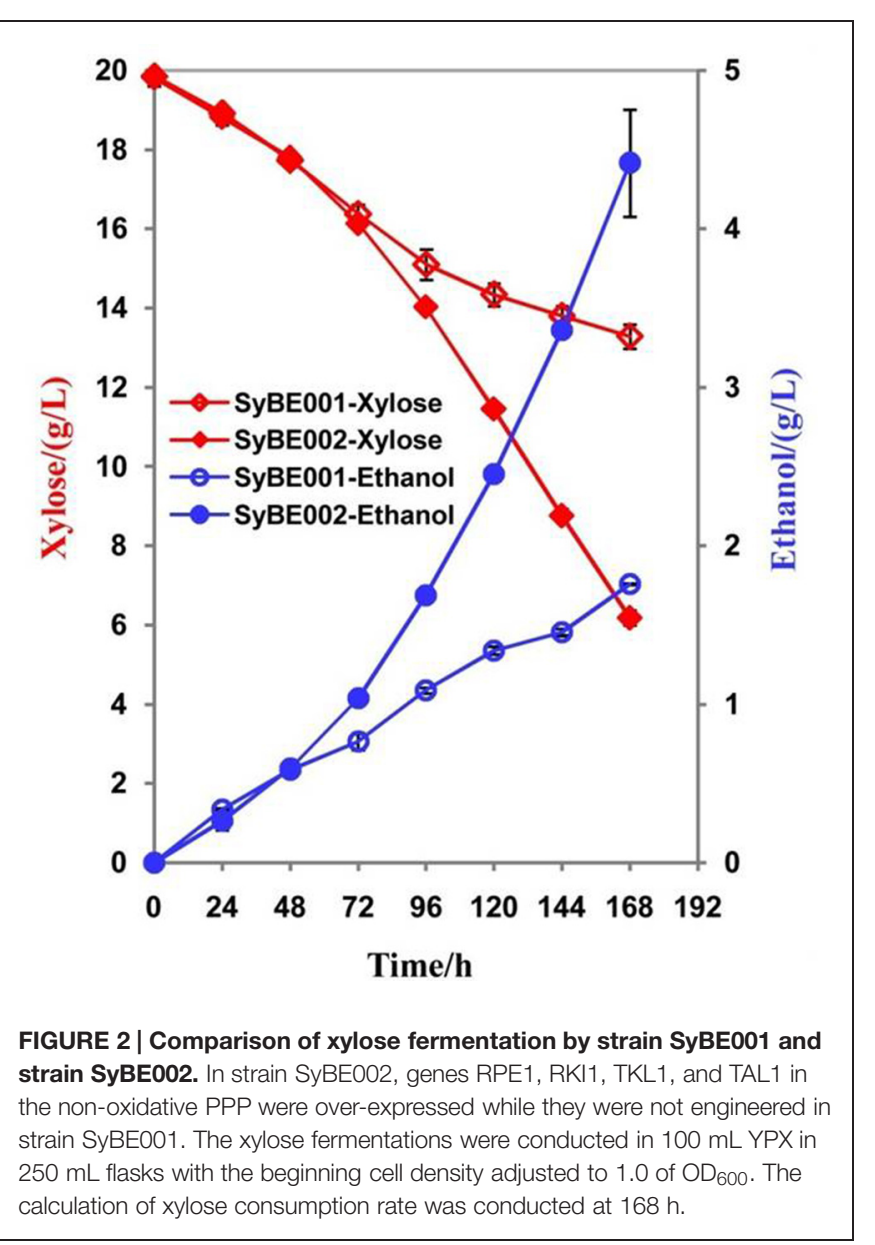

strain SyBE003 metabolized more than 95\% of the total xylose, while strain SyBE002 consumed only 7\% (Figure 3A). After $48 \mathrm{~h}$, SyBE003 finished consumption of all xylose and produced $8.47 \mathrm{~g} / \mathrm{L}$ ethanol with a yield of $0.40 \mathrm{~g} / \mathrm{g}$ xylose, while SyBE002 consumed only $10 \%$ of the total xylose (Table 2; Figure 3A), indicating that xylose utilization was increased more than 10 times after adaptation. The xylitol yield in SyBE003 was $0.01 \mathrm{~g} / \mathrm{g}$, indicating that almost all the assimilated xylose was utilized instead of being secreted as a byproduct, while strain SyBE002 had a 14-fold higher xylitol yield (Table 2). In addition, the glycerol yield in SyBE003 was $0.05 \mathrm{~g} / \mathrm{g}$ xylose, which was 37.5\% lower than that of SyBE002 (Table 2).

The performance of SyBE003 was also examined under a higher concentration of xylose (40 g/L) (Figure 3). To achieve a higher ethanol productivity, the initial cell density was elevated to 2.0 of $\mathrm{OD}_{600}$ (Figure 3B). After 36 h, 96\% xylose was consumed by SyBE003, and the xylose consumption rate increased up to $\sim 1 \mathrm{~g} / \mathrm{L} / \mathrm{h}$. In contrast, only $5 \%$ xylose was utilized by SyBE002. The xylitol yield and glycerol yield in SyBE003 decreased by eightfold and 44\% compared to those in SyBE002, respectively. Consistently, the ethanol yield in SyBE003 (0.43 g/g) was 48\% higher than that in SyBE002 (0.29 g/g) (Table 2). These results clearly demonstrated that the performance of the evolved strain SyBE003 on xylose was significantly improved after evolution.

\section{Fermentation of SyBE002 and SyBE003 on Mixed Sugars}

To achieve economical feasibility of ethanol fermentation on lignocellulosic hydrolysates, efficient co-utilization of xylose, and glucose is necessary. Thus, we characterized the performance of SyBE003 on mixed sugars. As shown in Figure 4, glucose was preferably consumed by both SyBE002 and SyBE003 during the first $12 \mathrm{~h}$ followed by the utilization of xylose. In SyBE003, 93\% xylose was consumed in $24 \mathrm{~h}$, while only $16 \%$ of the xylose was utilized by SyBE002. The final ethanol yield in SyBE003 reached $0.41 \mathrm{~g} / \mathrm{g}$ sugar, $8 \%$ higher than that in SyBE002 $(0.38 \mathrm{~g} / \mathrm{g}$ sugar) (Figure 4). The xylitol yield of SyBE003 was 13-fold lower than that of SyBE002 whereas the glycerol yield of both strains was almost the same (Table 2). Taken together, the results demonstrated that the xylose-fermenting $S$. cerevisiae SyBE003 obtained through evolutionary engineering was an efficient ethanol producer on mixed sugars of glucose and xylose.

\section{The Expression Profile of Genes in Xylose Metabolism}

No mutations were observed in the promoters and gene sequences of XylA and XKS1(sequencing primers in Supplementary Table S5). To investigate the transcriptional changes of SyBE002 after evolution, the expression of genes in PPP, glycolysis, and the tricarboxylic acid (TCA) cycle was monitored using real-time quantitative RT-PCR. As shown in Figure 5 (raw data in Supplementary Data 2), most of the genes in the initial xylose metabolic pathway showed no significant differences in transcription level except XylA, XKS1, TKL2, and ZWF1.

The expression level of XylA in SyBE003 was 0.53-fold of that in SyBE002. Despite transcriptional decrease of XylA, the enzymatic activity of XI in SyBE003 $(0.255 \pm 0.020 \mathrm{U} / \mathrm{mg})$ was comparable to that in SyBE002 $(0.263 \pm 0.022 \mathrm{U} / \mathrm{mg})$. The underlying mechanism for this inconsistency will be investigated in the following study.

The expression level of XKS1 increased by threefold in SyBE003 compared to SyBE002, representing the requirement of abundant expression of XKS1 for efficient xylose metabolism. In the non-oxidative PPP, the expression levels of most genes did not changed significantly except for $T K L 2$, which encodes the minor isoform of transketolase. The expression level of TKL2 was downregulated in SyBE003 along with the decreased expression of TKL1 encoding the major isoform of transketolase. Gene ZWF1 coding for glucose-6-phosphate dehydrogenase was also downregulated in SyBE003, which was indicative of a depressed activity of the oxidative PPP part in the unique style of xylose metabolism (Figure 5).

The key genes PGK1 and PYK1 in glycolysis showed lower levels of mRNA transcripts in SyBE003 compared with those in SyBE002 (Figure 5). The expression of gene PDC1 coding for the major isozyme of pyruvate decarboxylase complex, which is responsible for acetic acid and ethanol production, was also down-regulated. Similarly, the genes in the TCA cycle such as CIT2, KGD1, SDH2, FUM1, and MDH1 exhibited dramatically reduced expression in SyBE003, indicating a 
A

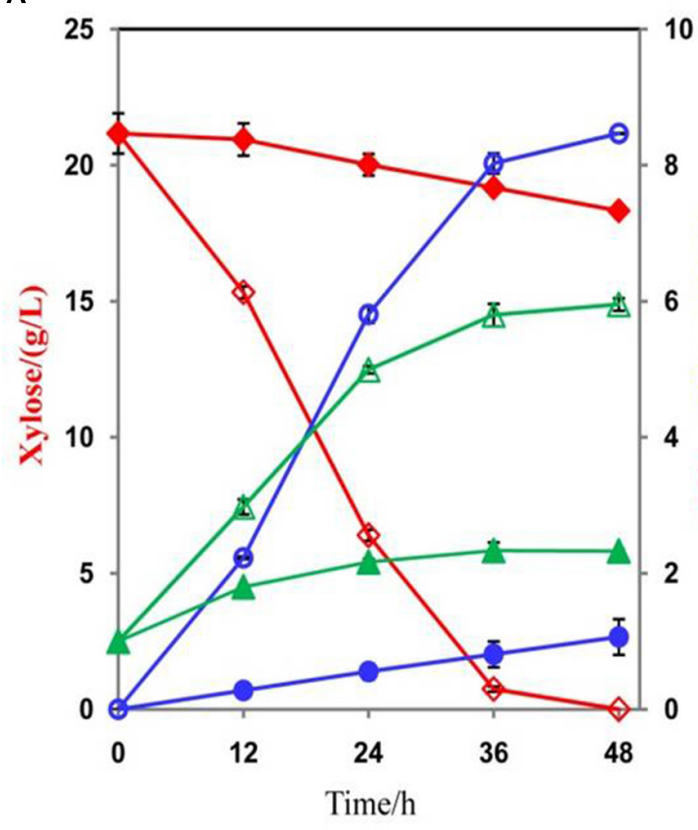

B

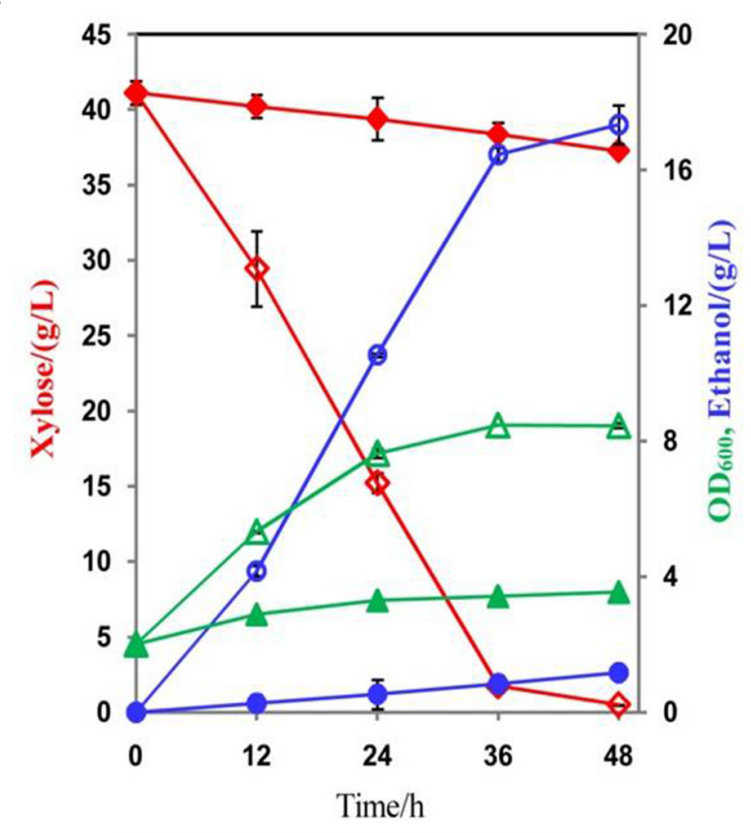

$\multimap$ SyBE002-Xylose
$\multimap$ SyBE003-Xylose

SyBE002-Ethanol

- - SyBE002-OD

$\triangle$ SyBE003-OD

FIGURE 3 | The ethanol fermentation by SyBE002 and SyBE003 on $\mathbf{2 0} \mathbf{~ g / L ~ x y l o s e ~ ( A ) ~ a n d ~} \mathbf{4 0} \mathbf{~ g / L ~ x y l o s e ~ ( B ) . ~ T h e ~ i n i t i a l ~ c e l l ~ d e n s i t y ~ w a s ~ a d j u s t e d ~ t o ~} 1.0$ of OD600. The fermentations were performed in $100 \mathrm{~mL}$ medium in 250-mL Erlenmeyer flasks. The data was the mean \pm SD of the duplicated experiments. The calculation of xylose consumption rate was performed at $48 \mathrm{~h}$.

TABLE 2 | Summary of the anaerobic batch fermentation by strain SyBE002 and the evolved strain SyBE003 on different carbon sources.

\begin{tabular}{lcccccc}
\hline & SyBE002 & SyBE003 & SyBE002 & SyBE003 & SyBE002 & SyBE003 \\
\hline Carbon source & $2 \%$ xylose & $2 \%$ xylose & $4 \%$ xylose & $4 \%$ xylose & $2 \%$ xylose+2\% glucose & $2 \%$ xylose+2\% glucose \\
Ethanol yield $(\mathrm{g} / \mathrm{g})$ & $0.30 \pm 0.03^{\mathrm{a}}$ & $0.40 \pm 0.00^{\mathrm{a}}$ & $0.29 \pm 0.00^{\mathrm{a}}$ & $0.43 \pm 0.01^{\mathrm{a}}$ & $0.38 \pm 0.01^{\mathrm{b}}$ & $0.41 \pm 0.02^{\mathrm{b}}$ \\
Xylitol yield $(\mathrm{g} / \mathrm{g})$ & $0.15 \pm 0.00^{\mathrm{a}}$ & $0.01 \pm 0.00^{\mathrm{a}}$ & $0.18 \pm 0.00^{\mathrm{a}}$ & $0.02 \pm 0.00^{\mathrm{a}}$ & $0.14 \pm 0.02^{\mathrm{b}}$ & $0.01 \pm 0.00^{\mathrm{b}}$ \\
Glycerol yield $(\mathrm{g} / \mathrm{g})$ & $0.08 \pm 0.00^{\mathrm{a}}$ & $0.05 \pm 0.00^{\mathrm{a}}$ & $0.09 \pm 0.01^{\mathrm{a}}$ & $0.05 \pm 0.01^{\mathrm{a}}$ & $0.05 \pm 0.00^{\mathrm{b}}$ & $0.04 \pm 0.00^{\mathrm{b}}$ \\
\hline
\end{tabular}

Values are presented as the average and standard deviation of two independent experiments.

aThe values were calculated by the concentrations of the metabolites measured at $48 \mathrm{~h}$.

${ }^{\mathrm{b}}$ The values were analyzed based on total sugars determined at $36 \mathrm{~h}$ in the fermentation.

decreased respiratory response to xylose, which was also reported in recombinant xylose-fermenting yeasts (Jin et al., 2004). On the contrary, the transcripts for the gluconeogenic enzymes ICL1 and FBP1 in SyBE003 were induced to 1.50- and 2.05-fold of the levels in SyBE002, respectively.

Overall, comparatively transcriptional profiling showed that the improved xylose fermentation involved decreased transcription burden of XylA, rearrangement of PPP, decreased glycolysis activity, repressed respiration activity, and enhanced gluconeogenesis.

\section{Effect of TKL2 Disruption on Xylose Fermentation}

To confirm the positive effect of decreased expression of TKL2, this gene was knocked out in SyBE002 and the resulting strain SyBE002-TKL2 $\Delta$ was compared with SyBE002 in terms of xylose fermentation (Figure 6). The results showed that SyBE002-TKL2 $\Delta$ consumed $13.0 \%$ more xylose than SyBE002 (Figure 6). The final ethanol production of SyBE002-TKL2 $\Delta$ was $13.0 \%$ higher than that of SyBE002. The ethanol, xylitol, and glycerol yields in SyBE002-TKL2 $\Delta$ were nearly identical to those in SyBE002. The results demonstrated that the decreased expression of TKL2 did improve xylose fermentation. Single disruption of TKL2 did not achieve a xylose-fermenting strain as efficient as SyBE003, indicating that the enhanced phenotype was associated with multiple genes besides TKL2.

\section{DISCUSSION}

In the present study, we constructed an efficient xylosefermenting S. cerevisiae SyBE003 through the combinatorial 

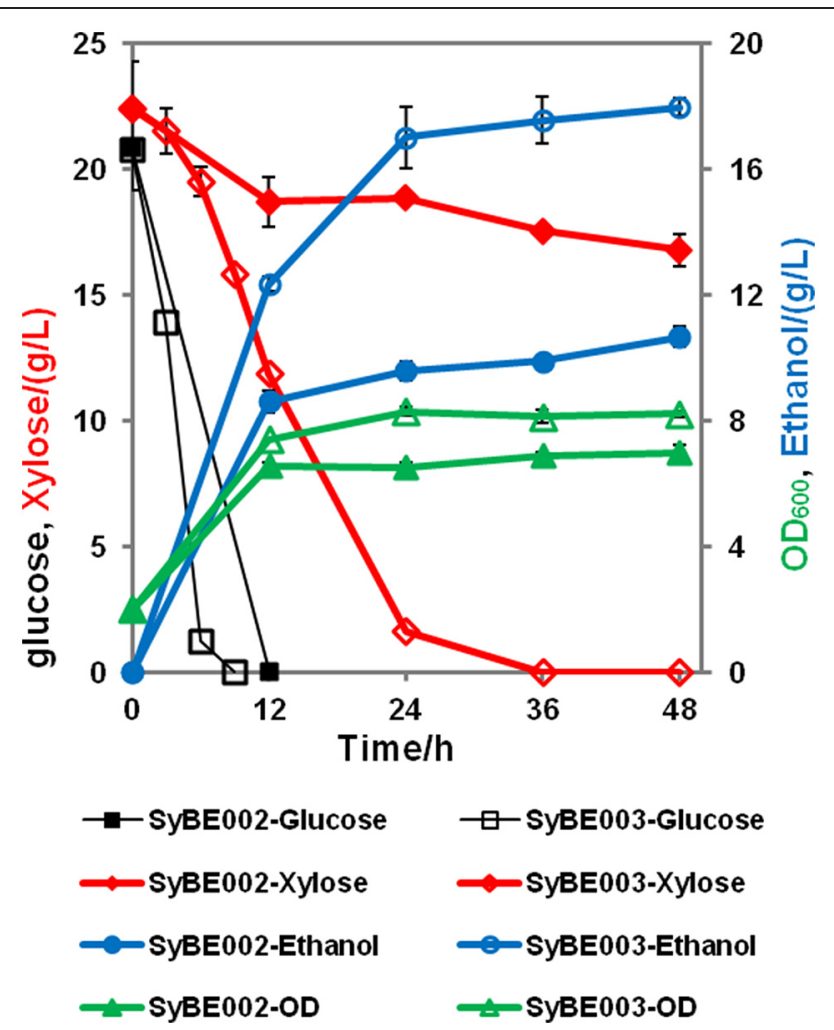

FIGURE 4 | Anaerobic batch fermentation by SyBE002 and SyBE003 on mixed xylose and glucose, $20 \mathrm{~g} / \mathrm{L}$ each. The initial cell density of inocula was 2.0 of $\mathrm{OD}_{600}$. The fermentations were carried out in $100 \mathrm{~mL}$ medium in 250-mL Erlenmeyer flasks. The data was the mean \pm SD of the duplicated experiments. The calculation of xylose consumption rate was carried out at $48 \mathrm{~h}$.

expression of key genes and evolutionary engineering. The strain SyBE003 can rapidly utilize xylose and produce ethanol with high yield. Initial rational design of the expression of $X y l A$ and XKS1 led to an optimal combination, in which XylA and XKS1 were expressed by TDH3p and TDH1p, respectively. Combinatorial modulation of expression of multiple genes through promoter shuffling is a widely used strategy to optimize metabolic pathways. Lu and Jeffries (2007) used MGPS (multiplegene-promoter shuffling) to successfully optimize the expression of TAL1, TKL1, and PYK1 for improved xylose fermentation. The 15000-fold increased taxadiene production was achieved in a recombinant $E$. coli through combined fine-tuning of the expression of genes in the mevalonic acid pathway and taxadiene biosynthesis pathway (Ajikumar et al., 2010). In this study, combinatorial optimization of XylA and XKS1 improved xylose utilization to some extent. Gene XKS1 showed a more important role in regulation of xylose utilization during the optimization process. In a previous study, increased expression of XKS1 improved cell growth and viability when S. cerevisiae was cultivated on xylulose (Richard et al., 2000). Overexpression of XKS1 in the XYL1 and XYL2-expresssing S. cerevisiae increased xylose consumption rate by more than onefold under anaerobic conditions (Toivari et al., 2001). The positive effect of XKS1 overexpression was also observed in a recombinant S. cerevisiae expressing XylA (Lee et al., 2012). However, excessive overexpression of XKS1 can also bring adverse effects on xylose metabolism and slow down xylose uptake, which has been reported (Jin et al., 2003; Matsushika and Sawayama, 2008).

Evolutionary engineering is an easy and effective method to reprogram the xylose metabolic pathway amid the limited understanding of transcriptional and post-transcriptional regulation of xylose metabolism so far. Many studies have reported the success of evolutionary engineering in improving xylose utilization. Through evolutionary engineering, improved utilization of xylose and arabinose was obtained after chemostat adaptation of $\sim 1800 \mathrm{~h}$ (Garcia Sanchez et al., 2010). The aerobic growth rate of xylose-fermenting yeast increased by threefold after adaptive evolution ( $\mathrm{Liu}$ and $\mathrm{Hu}, 2010$ ). In the present study, the use of evolutionary engineering for xylose utilization improvement is directly related to the growth rate. It was reported that evolutionary engineering of growth-coupled metabolic engineering designs can lead to a significant increase in the production rate and a reduction in byproduct formation (Fong et al., 2005). The evolved strain SyBE003 showed not only significant improvement in growth rate but also an obvious reduction in xylitol production (Table 2).

Microorganisms are able to adapt rapidly to different environmental conditions such as carbon source-limited condition. Under a given environment, deleterious and beneficial mutations might occur. The deleterious mutations will be removed by the selective pressure from the environment and accumulation of beneficial mutations will occur. The evolution patterns are hard to predict and random factors such as founder events greatly determine the trait of the population (Simões et al., 2008; Kolbe et al., 2012). Different colonies might have different mutations that can contribute to improved xylosefermenting property. Physiological fitness can be obtained through different shifts in genomic sequence space (Conrad et al., 2011). Comparative systematic analysis of isolates from intermediate steps of the evolutionary process such as expression profile and proteome profile will help us to understand the mechanism of evolutionary procedure.

The comparison between evolved strains and parent strains at transcriptional levels has provided an opportunity for establishing links between genotype and phenotype, which allows for rational approaches to further modifications (Hong et al., 2011). Transcriptional analysis of a recombinant xylose-fermenting strain TMB3399 and the mutant TMB3400 demonstrated that the improved performance involved xylose transport, initial xylose metabolism and PPP (Wahlbom et al., 2003). New putative bottlenecks in xylose metabolism were identified by proteomic analysis (Karhumaa et al., 2009). In this study, through real-time RT-PCR analysis of SyBE002 and SyBE003, some potential bottlenecks were identified in xylose metabolism, which offered new gene targets for further metabolic engineering of the XI pathway.

The transcriptional level of $X y l A$ was down-regulated in the evolved strain, which might be ascribed to the decrease in copy number because of the integration into the genomic DNA from a multicopy plasmid, about 60 in copy number (Futcher, 1986). 


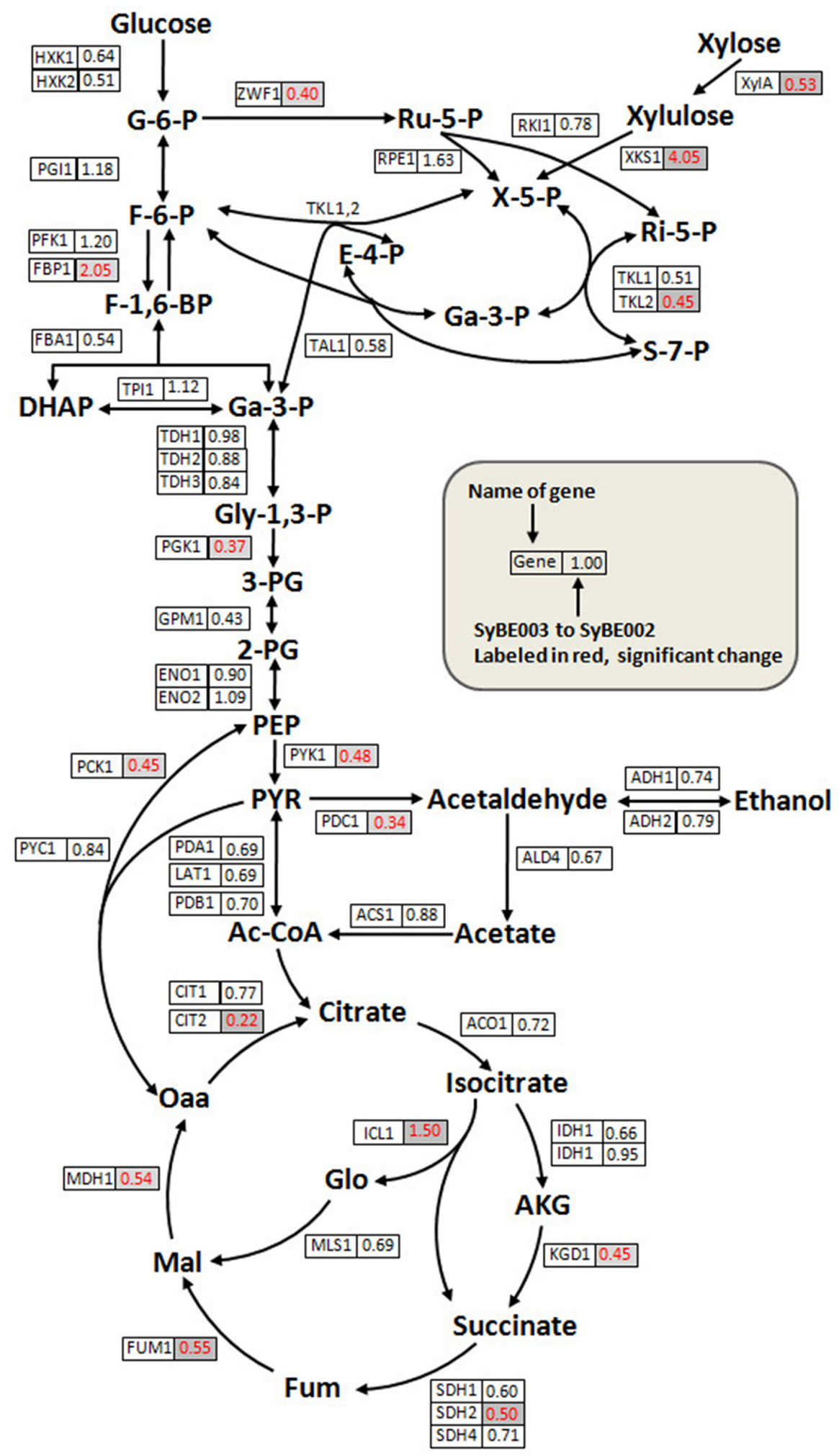

FIGURE 5 | Quantitative analysis of transcriptional levels of genes in the xylose metabolic pathway and the central carbon metabolism pathway. Cells of SyBE002 and SyBE003 were cultivated at $20 \mathrm{~g} / \mathrm{L}$ xylose and harvested after $18 \mathrm{~h}$ of fermentation for transcriptional analysis. The name of each gene is shown on the left side of the boxes. The values on the right side of the boxes indicate the ratios of transcriptional levels in SyBE003 to those in SyBE002. 


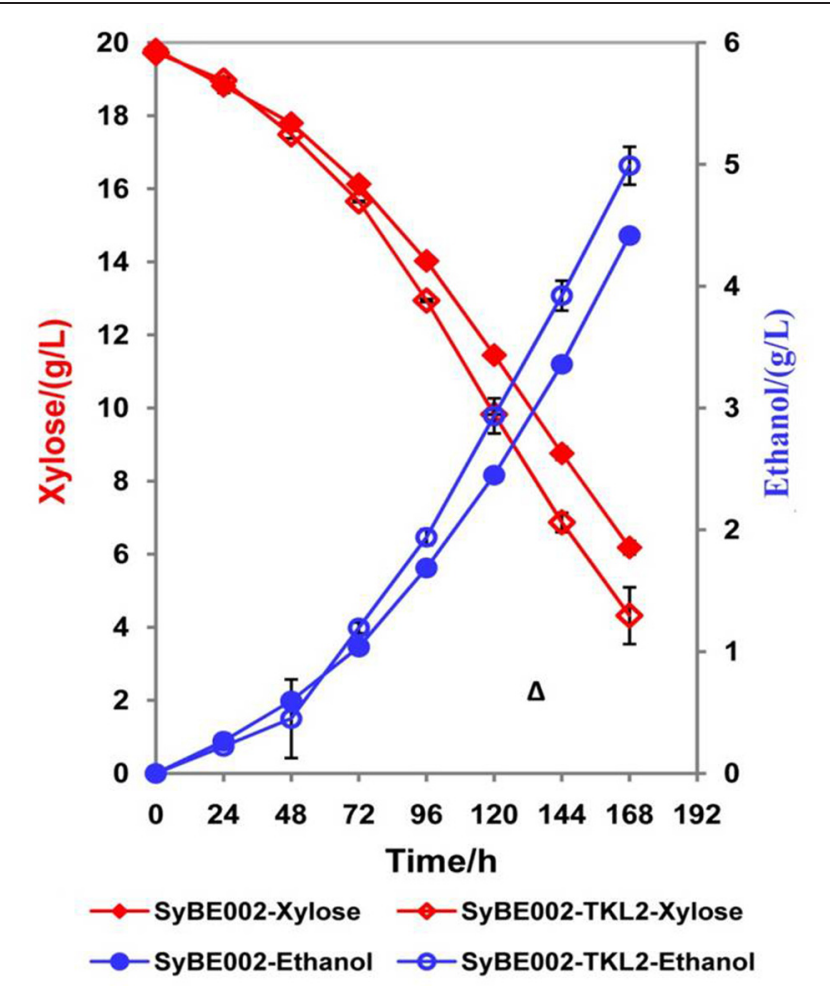

FIGURE 6 | Deletion of TKL2 accelerates xylose fermentation in SyBE002. Strain SyBE002-TKL2 $\Delta$, in which gene TKL2 was knocked out, and SyBE002 were cultivated in YPX medium with $20 \mathrm{~g} / \mathrm{L}$ xylose under anaerobic conditions. The initial cell density of inocula was calibrated to 1.0 of OD600. The results shown were the mean value of duplicate experiments. The calculation of xylose consumption rate was performed at $168 \mathrm{~h}$.

In our study, extraction of the plasmid pTDH3XI carrying $X y l A$ from SyBE003 failed while it was successful from SyBE002. Moreover, $X y l A$ fragment could be amplified using genomic DNA from as SyBE003 the PCR template (data not shown). Early research has also observed that $X y l A$ can be recombined into chromosome and duplicated in evolved strains (Zhou et al., 2012). These results suggested that integration of $X y l A$ into chromosome might happen during the adaptation. Reducing the transcriptional burden has been an important means to optimize the metabolic pathway (Dueber et al., 2009; Ajikumar et al., 2010; Bond-Watts et al., 2011). Thus, efficient xylose utilization requires optimal expression of $X y l A$. Alper and Coworkers developed a XylA mutant (E15D, E114G, E129D, T142S, A177T, and V433I) through directed evolution, which was $77 \%$ more active than the wild type (Lee et al., 2012). Expression of the mutant by a single copy plasmid improved ethanol production by $88 \%$. Expression of the $X y l A$ mutant could achieve a high enough XI activity under a low transcript level, which could additionally improve xylose fermentation.

Comparison of gene expression also indicated reprogramming of TKL. PPP has a lower flux capacity than glycolysis, which contributes to the lower consumption rate of xylose than that of glucose (Kuyper et al., 2005a; Chu and Lee, 2007; Matsushika et al., 2009; Shen et al., 2015). Thus, metabolic engineering of xylose metabolism often involves overexpression of genes in the non-oxidative PPP. In this study, the enhanced expression of RPE1, RKI1, TKL1, and TAL1 indeed increased xylose consumption rate (Figure 2). In PPP, TKL1 is important for the production of the precursors needed for the biosynthesis of aromatic amino acids and nucleic acids. However, excessive expression of TKL1 can cause the imbalance between PPP and the glycolytic pathway (Matsushika et al., 2012). The expression level of TKL1, which was under the control of the strongest promoter TDH3, might be too high in this study. Therefore, TKL1 and TKL2 were down-regulated to keep the balance of PPP and the glycolytic pathway during the evolution process. Metzger observed that overexpression of the transketolase-encoding gene from Scheffersomyces stipitis caused slow xylose consumption in a xylose-utilizing S. cerevisiae (Metzger and Hollenberg, 1994). The rates of xylose consumption and ethanol production were slightly impaired when TKL1 or TKL2 was over-expressed in the recombinant yeast expressing XYL1/XYL2/XKS1 (Matsushika et al., 2012). So far, fine-tuning the expression of genes in PPP has never been reported. The result reported in this study indicates that fine-tuning the expression of a gene such as TKL may be an important alternative to optimize xylose metabolism in recombinant S. cerevisiae.

Besides reprogramming of PPP, the transcriptional levels of PGK1 and PYK1 were down-regulated in SyBE003. Pyruvate kinase, encoded by PYK1, catalyzes ATP generation in glycolysis and is a sensor of the cytosolic ATP/ADP ratio (Larsson et al., 2000). 3-phosphoglycerate kinase, encoded by the gene $P G K 1$, is another enzyme catalyzing the formation of ATP in glycolysis. Expression levels of PYK1 and PGK1 are indicators of ATP concentration in cells. ATP is a co-substrate of many kinases such as XK and any imbalance between ATP consumption and generation will decrease metabolic fluxes and eventually shut down the pathway. In SyBE002 the xylose metabolism was restricted and excessive ATP might exist, causing the imbalance of ATP pool. Thus, the decrease in expression of PYK1 and PGK1 in SyBE003 might achieve the balance of ATP pool under anaerobic xylose fermentation. Moreover, the increase of XKS1 expression was observed in SyBE003, whose enzyme product XK consumed ATP. This is consistent with a previous study showing that a higher ATP level was observed in the strain with slower xylose consumption (Toivari et al., 2001).

Although potential bottlenecks were identified in PPP, glycolysis, gluconeogenesis, and the TCA cycle in the present study, other limitations apart from these pathways need clarification. Many transcription factors have been reported to be associated with the regulation of non-favored sugars such as xylose, arabinose, and galactose (Salusjarvi et al., 2008; Turcotte et al., 2010). In one study, the transcription factor RGT1 responsible for regulation of HXT genes showed higher expression in xylose-grown yeast cells than those grown on glucose, providing possible clues in engineering xylose transportation for improved xylose utilization (Salusjarvi et al., 2008). In another instance, the expression of a mutant transcription factor RAS2 (Tyr112) increased growth rate on galactose in S. cerevisiae (Hong et al., 2011). Therefore, global identification of metabolic bottlenecks in xylose metabolism will 
provide a comprehensive understanding of xylose metabolism and regulation.

The xylose-fermenting $S$. cerevisiae SyBE003 is derived from a laboratory strain L2612 of limited resistance to multiple inhibitors present in lignocellulosic hydrolysates. These inhibitors will greatly restrain cell growth and ethanol productivity especially during the period of xylose consumption (Palmqvist and Hahn-Hagerdal, 2000; Zhu et al., 2015). Increasing the tolerance to multiple inhibitors is the urgent challenge to construct a robust strain that can efficiently produce ethanol from biomass hydrolysates.

\section{CONCLUSION}

We obtained an efficient xylose-fermenting strain SyBE003 through the combinatorial design of key genes and evolutionary engineering. The optimization process identified an optimal combination of $X y l A$ and $X K S 1$. Evolutionary engineering is a feasible approach to rapidly reconstruct

\section{REFERENCES}

Ajikumar, P. K., Xiao, W. H., Tyo, K. E. J., Wang, Y., Simeon, F., Leonard, E., et al. (2010). Isoprenoid pathway optimization for taxol precursor overproduction in Escherichia coli. Science 330, 70-74. doi: 10.1126/science.11 91652

Bengtsson, O., Hahn-Hagerdal, B., and Gorwa-Grauslund, M. F. (2009). Xylose reductase from pichia stipitis with altered coenzyme preference improves ethanolic xylose fermentation by recombinant Saccharomyces cerevisiae. Biotechnol. Biofuels 2, 9. doi: 10.1186/1754-6834-2-9

Bond-Watts, B. B., Bellerose, R. J., and Chang, M. C. Y. (2011). Enzyme mechanism as a kinetic control element for designing synthetic biofuel pathways. Nat. Chem. Biol. 7, 222-227. doi: 10.1038/nchembio.537

Brat, D., and Boles, E. (2013). Isobutanol production from d-xylose by recombinant Saccharomyces cerevisiae. FEMS Yeast Res. 13, 241-244. doi: 10.1111/15671364.12028

Brat, D., Boles, E., and Wiedemann, B. (2009). Functional expression of a bacterial xylose isomerase in Saccharomyces cerevisiae. Appl. Environ. Microbiol. 75, 2304-2311. doi: 10.1128/AEM.02522-08

Chu, B. C., and Lee, H. (2007). Genetic improvement of Saccharomyces cerevisiae for xylose fermentation. Biotechnol. Adv. 25, 425-441. doi: 10.1016/j.biotechadv.2007.04.001

Conrad, T. M., Lewis, N. E., and Palsson, B. O. (2011). Microbial laboratory evolution in the era of genome-scale science. Mol. Syst. Biol. 7, 509. doi: $10.1038 / \mathrm{msb} .2011 .42$

Demeke, M. M., Foulquie-Moreno, M. R., Dumortier, F., and Thevelein, J. M. (2015). Rapid evolution of recombinant Saccharomyces cerevisiae for xylose fermentation through formation of extra-chromosomal circular DNA. PLoS Genet. 11:e1005010. doi: 10.1371/journal.pgen.1005010

Du, J., Yuan, Y., Si, T., Lian, J., and Zhao, H. (2012). Customized optimization of metabolic pathways by combinatorial transcriptional engineering. Nucleic Acids Res. 40, e142. doi: 10.1093/nar/gks549

Dueber, J. E., Wu, G. C., Malmirchegini, G. R., Moon, T. S., Petzold, C. J., Ullal, A. V., et al. (2009). Synthetic protein scaffolds provide modular control over metabolic flux. Nat. Biotechnol. 27, 753-759. doi: 10.1038/nbt.1557

Fong, S. S., Burgard, A. P., Herring, C. D., Knight, E. M., Blattner, F. R., Maranas, C. D., et al. (2005). In silico design and adaptive evolution of Escherichia coli for production of lactic acid. Biotechnol. Bioeng. 91, 643-648. doi: 10.1002/bit.20542

Futcher, A. B. (1986). Copynumber amplification of the $2 \mu \mathrm{m}$ circle plasmid of Saccharomyces cerevisiae. J. Theor. Biol. 119, 197-204. doi: 10.1016/S00225193(86)80074-1 an efficient strain for xylose fermentation, and the xylose utilization rate increased about 10 -fold during the adaptation.

\section{ACKNOWLEDGMENTS}

The authors are grateful for the financial support from the Ministry of Science and Technology of China ("973" Program: 2013CB733601 and 2014CB745102, “863” Program: 2012AA02A701).We thank Professor Thomas Jeffries at University of Wisconsin-Madison for providing yeast strain L2612.

\section{SUPPLEMENTARY MATERIAL}

The Supplementary Material for this article can be found online at: http://journal.frontiersin.org/article/10.3389/fmicb. 2015.01165

Garcia Sanchez, R., Karhumaa, K., Fonseca, C., Sanchez Nogue, V., Almeida, J. R., Larsson, C. U., et al. (2010). Improved xylose and arabinose utilization by an industrial recombinant Saccharomyces cerevisiae strain using evolutionary engineering. Biotechnol. Biofuels 3, 13. doi: 10.1186/1754-6834-3-13

Gietz, R. D., Schiestl, R. H., Willems, A. R., and Woods, R. A. (1995). Studies on the transformation of intact yeast cells by the LiAc/SS-DNA/PEG procedure. Yeast 11, 355-360. doi: 10.1002/yea.320110408

Ha, S.-J., Kim, S. R., Choi, J.-H., Park, M. S., and Jin, Y.-S. (2011). Xylitol does not inhibit xylose fermentation by engineered Saccharomyces cerevisiae expressing xyla as severely as it inhibits xylose isomerase reaction in vitro. Appl. Microbiol. Biotechnol. 92, 77-84. doi: 10.1007/s00253-011-3345-9

Hong, K. K., Vongsangnak, W., Vemuri, G. N., and Nielsen, J. (2011). Unravelling evolutionary strategies of yeast for improving galactose utilization through integrated systems level analysis. Proc. Natl. Acad. Sci. U.S.A. 108, 12179-12184. doi: 10.1073/pnas.1103219108

Jeppsson, M., Bengtsson, O., Franke, K., Lee, H., Hahn-Hagerdal, R., and GorwaGrauslund, M. F. (2006). The expression of a pichia stipitis xylose reductase mutant with higher $\mathrm{km}$ for nadph increases ethanol production from xylose in recombinant Saccharomyces cerevisiae. Biotechnol. Bioeng. 93, 665-673. doi: 10.1002/bit.20737

Jin, Y. S., Laplaza, J. M., and Jeffries, T. W. (2004). Saccharomyces cerevisiae engineered for xylose metabolism exhibits a respiratory response. Appl. Environ. Microbiol. 70, 6816-6825. doi: 10.1128/AEM.70.11.6816-6825.2004

Jin, Y. S., Ni, H. Y., Laplaza, J. M., and Jeffries, T. W. (2003). Optimal growth and ethanol production from xylose by recombinant Saccharomyces cerevisiae require moderate d-xylulokinase activity. Appl. Environ. Microbiol. 69, 495-503. doi: 10.1128/AEM.69.1.495-503.2003

Karhumaa, K., Fromanger, R., Hahn-Hägerdal, B., and Gorwa-Grauslund, M.-F. (2007a). High activity of xylose reductase and xylitol dehydrogenase improves xylose fermentation by recombinant Saccharomyces cerevisiae. Appl. Microbiol. Biotechnol. 73, 1039-1046. doi: 10.1007/s00253-006-0575-3

Karhumaa, K., Sanchez, R. G., Hahn-Hagerdal, B., and Gorwa-Grauslund, M. F. (2007b). Comparison of the xylose reductase-xylitol dehydrogenase and the xylose isomerase pathways for xylose fermentation by recombinant Saccharomyces cerevisiae. Microb. Cell Fact 6, 5. doi: 10.1186/1475-2859-6-5

Karhumaa, K., Hahn-Hagerdal, B., and Gorwa-Grauslund, M. F. (2005). Investigation of limiting metabolic steps in the utilization of xylose by recombinant Saccharomyces cerevisiae using metabolic engineering. Yeast 22, 359-368. doi: 10.1002/yea.1216

Karhumaa, K., Pahlman, A. K., Hahn-Hagerdal, B., Levander, F., and GorwaGrauslund, M. F. (2009). Proteome analysis of the xylose-fermenting mutant yeast strain tmb 3400. Yeast 26, 371-382. doi: 10.1002/yea.1673 
Kim, B., Du, J., Eriksen, D. T., and Zhao, H. (2013). Combinatorial design of a highly efficient xylose-utilizing pathway in Saccharomyces cerevisiae for the production of cellulosic biofuels. Appl. Environ. Microbiol. 79, 931-941. doi: 10.1128/AEM.02736-12

Kolbe, J. J., Leal, M., Schoener, T. W., Spiller, D. A., and Losos, J. B. (2012). Founder effects persist despite adaptive differentiation: a field experiment with lizards. Science 335, 1086-1089. doi: 10.1126/science. 1209566

Kuyper, M., Harhangi, H. R., Stave, A. K., Winkler, A. A., Jetten, M. S., de Laat, W. T., et al. (2003). High-level functional expression of a fungal xylose isomerase: the key to efficient ethanolic fermentation of xylose by Saccharomyces cerevisiae? FEMS Yeast Res. 4, 69-78. doi: 10.1016/S15671356(03)00141-7

Kuyper, M., Hartog, M. M., Toirkens, M. J., Almering, M. J., Winkler, A. A., van Dijken, J. P., et al. (2005a). Metabolic engineering of a xyloseisomerase-expressing Saccharomyces cerevisiae strain for rapid anaerobic xylose fermentation. FEMS Yeast Res. 5, 399-409. doi: 10.1016/j.femsyr.2004. 09.010

Kuyper, M., Toirkens, M. J., Diderich, J. A., Winkler, A. A., van Dijken, J. P., and Pronk, J. T. (2005b). Evolutionary engineering of mixed-sugar utilization by a xylose-fermenting Saccharomyces cerevisiae strain. FEMS Yeast Res. 5, 925-934. doi: 10.1016/j.femsyr.2005.04.004

Larsson, C., Pahlman, I. L., and Gustafsson, L. (2000). The importance of atp as a regulator of glycolytic flux in Saccharomyces cerevisiae. Yeast 16, 797-809. doi: 10.1002/1097-0061(20000630)16:9<797::AID-YEA553>3.0.CO;2-5

Lee, S. M., Jellison, T., and Alper, H. S. (2012). Directed evolution of xylose isomerase for improved xylose catabolism and fermentation in the yeast Saccharomyces cerevisiae. Appl. Environ. Microbiol. 78, 5708-5716. doi: 10.1128/AEM.01419-12

Lee, S. M., Jellison, T., and Alper, H. S. (2014). Systematic and evolutionary engineering of a xylose isomerase-based pathway in Saccharomyces cerevisiae for efficient conversion yields. Biotechnol. Biofuels 7, 122. doi: 10.1186/s13068014-0122-x

Li, B. Z., Balan, V., Yuan, Y. J., and Dale, B. E. (2010). Process optimization to convert forage and sweet sorghum bagasse to ethanol based on ammonia fiber expansion (afex) pretreatment. Bioresour. Technol. 101, 1285-1292. doi: 10.1016/j.biortech.2009.09.044

Liu, E. K., and Hu, Y. (2010). Construction of a xylose-fermenting Saccharomyces cerevisiae strain by combined approaches of genetic engineering, chemical mutagenesis and evolutionary adaptation. Biochem. Eng. J. 48, 204-210. doi: 10.1016/j.bej.2009.10.011

Lonn, A., Traff-Bjerre, K. L., Otero, R. R. C., van Zyl, W. H., and HahnHagerdal, B. (2003). Xylose isomerase activity influences xylose fermentation with recombinant Saccharomyces cerevisiae strains expressing mutated xyla from Thermus thermophilus. Enzyme Microb. Technol. 32, 567-573. doi: 10.1016/S0141-0229(03)00024-3

Lu, C., and Jeffries, T. (2007). Shuffling of promoters for multiple genes to optimize xylose fermentation in an engineered Saccharomyces cerevisiae strain. Appl. Environ. Microbiol. 73, 6072-6077. doi: 10.1128/AEM. 00955-07

Matsushika, A., Goshima, T., Fujii, T., Inoue, H., Sawayama, S., and Yano, S. (2012). Characterization of non-oxidative transaldolase and transketolase enzymes in the pentose phosphate pathway with regard to xylose utilization by recombinant Saccharomyces cerevisiae. Enzyme Microb. Technol. 51, 16-25. doi: 10.1016/j.enzmictec.2012.03.008

Matsushika, A., Inoue, H., Kodaki, T., and Sawayama, S. (2009). Ethanol production from xylose in engineered Saccharomyces cerevisiae strains: current state and perspectives. Appl. Microbiol. Biotechnol. 84, 37-53. doi: 10.1007/s00253-009-2101-x

Matsushika, A., and Sawayama, S. (2008). Efficient bioethanol production from xylose by recombinant Saccharomyces cerevisiae requires high activity of xylose reductase and moderate xylulokinase activity. J. Biosci. Bioeng. 106, 306-309. doi: $10.1263 /$ jbb. 106.306

Matsushika, A., Watanabe, S., Kodaki, T., Makino, K., Inoue, H., Murakami, K., et al. (2008). Expression of protein engineered nadp plus -dependent xylitol dehydrogenase increases ethanol production from xylose in recombinant Saccharomyces cerevisiae. Appl. Microbiol. Biotechnol. 81, 243-255. doi: 10.1007/s00253-008-1649-1
Metzger, M. H., and Hollenberg, C. P. (1994). Isolation and characterization of the pichia stipitis transketolase gene and expression in a xyloseutilising Saccharomyces cerevisiae transformant. Appl. Microbiol. Biotechnol. 42, 319-325. doi: 10.1007/s002530050257

Nijland, J. G., Shin, H. Y., de Jong, R. M., De Waal, P. P., Klaassen, P., and Driessen, A. J. M. (2014). Engineering of an endogenous hexose transporter into a specific d-xylose transporter facilitates glucose-xylose co-consumption in Saccharomyces cerevisiae. Biotechnol. Biofuels 7, 168. doi: 10.1186/s13068-0140168-9

Palmqvist, E., and Hahn-Hagerdal, B. (2000). Fermentation of lignocellulosic hydrolysates. I: inhibition and detoxification. Bioresour. Technol. 74, 17-24.

Petschacher, B., and Nidetzky, B. (2008). Altering the coenzyme preference of xylose reductase to favor utilization of nadh enhances ethanol yield from xylose in a metabolically engineered strain of Saccharomyces cerevisiae. Microb. Cell Fact. 7, 9. doi: 10.1186/1475-2859-7-9

Qin, L., Liu, Z. H., Li, B. Z., Dale, B. E., and Yuan, Y. J. (2012). Mass balance and transformation of corn stover by pretreatment with different dilute organic acids. Bioresour. Technol. 112, 319-326. doi: 10.1016/j.biortech.2012.02.134

Richard, P., Toivari, M. H., and Penttila, M. (2000). The role of xylulokinase in Saccharomyces cerevisiae xylulose catabolism. FEMS Microbiol. Lett. 190, 39-43. doi: 10.1111/j.1574-6968.2000.tb09259.x

Runquist, D., Fonseca, C., Radstrom, P., Spencer-Martins, I., and HahnHagerdal, B. (2009). Expression of the gxf1 transporter from Candida intermedia improves fermentation performance in recombinant xyloseutilizing Saccharomyces cerevisiae. Appl. Microbiol. Biotechnol. 82, 123-130. doi: 10.1007/s00253-008-1773-y

Salusjarvi, L., Kankainen, M., Soliymani, R., Pitkanen, J. P., Penttila, M., and Ruohonen, L. (2008). Regulation of xylose metabolism in recombinant Saccharomyces cerevisiae. Microb. Cell Fact. 7, 18. doi: 10.1186/1475-2859-7-18

Scalcinati, G., Otero, J. M., Van Vleet, J. R. H., Jeffries, T. W., Olsson, L., and Nielsen, J. (2012). Evolutionary engineering of Saccharomyces cerevisiae for efficient aerobic xylose consumption. FEMS Yeast Res. 12, 582-597. doi: 10.1111/j.1567-1364.2012.00808.x

Schmittgen, T. D., and Livak, K. J. (2008). Analyzing real-time pcr data by the comparative ct method. Nat. Protoc. 3, 1101-1108. doi: 10.1038/nprot.2008.73

Shen, M. H., Song, H., Li, B. Z., and Yuan, Y. J. (2015). Deletion of d-ribulose5-phosphate 3-epimerase (rpel) induces simultaneous utilization of xylose and glucose in xylose-utilizing Saccharomyces cerevisiae. Biotechnol. Lett. 37, 1031-1036. doi: 10.1007/s10529-014-1759-Z

Simões, P., Santos, J., Fragata, I., Mueller, L. D., Rose, M. R., and Matos, M. (2008). How repeatable is adaptive evolution? The role of geographical origin and founder effects in laboratory adaptation. Evolution 62, 1817-1829. doi: 10.1111/j.1558-5646.2008.00423.x

Toivari, M. H., Aristidou, A., Ruohonen, L., and Penttila, M. (2001). Conversion of xylose to ethanol by recombinant Saccharomyces cerevisiae: importance of xylulokinase (xks1) and oxygen availability. Metab. Eng. 3, 236-249. doi: 10.1006/mben.2000.0191

Turcotte, B., Liang, X. B., Robert, F., and Soontorngun, N. (2010). Transcriptional regulation of nonfermentable carbon utilization in budding yeast. FEMS Yeast Res. 10, 2-13. doi: 10.1111/j.1567-1364.2009.00555.x

Wahlbom, C. F., Otero, R. R. C., van Zyl, W. H., Hahn-Hagerdal, B., and Jonsson, L. J. (2003). Molecular analysis of a Saccharomyces cerevisiae mutant with improved ability to utilize xylose shows enhanced expression of proteins involved in transport, initial xylose metabolism, and the pentose phosphate pathway. Appl. Environ. Microbiol. 69, 740-746. doi: 10.1128/AEM.69.2.740746.2003

Wang, C., Bao, X., Li, Y., Jiao, C., Hou, J., Zhang, Q., et al. (2015). Cloning and characterization of heterologous transporters in Saccharomyces cerevisiae and identification of important amino acids for xylose utilization. Metab. Eng. 30, 79-88. doi: 10.1016/j.ymben.2015.04.007

Wang, X., Jin, M., Balan, V., Jones, A. D., Li, X., Li, B. Z., et al. (2014). Comparative metabolic profiling revealed limitations in xylose-fermenting yeast during cofermentation of glucose and xylose in the presence of inhibitors. Biotechnol. Bioeng. 111, 152-164. doi: 10.1002/bit.24992

Wisselink, H. W., Cipollina, C., Oud, B., Crimi, B., Heijnen, J. J., Pronk, J. T., et al. (2010). Metabolome, transcriptome and metabolic flux analysis of arabinose fermentation by engineered Saccharomyces cerevisiae. Metab. Eng. 12, 537-551. doi: 10.1016/j.ymben.2010.08.003 
Zha, J., Hu, M. L., Shen, M. H., Li, B. Z., Wang, J. Y., and Yuan, Y. J. (2012). Balance of xyl1 and xyl2 expression in different yeast chassis for improved xylose fermentation. Front. Microbiol. 3:355. doi: 10.3389/fmicb.2012. 00355

Zha, J., Li, B. Z., Shen, M. H., Hu, M. L., Song, H., and Yuan, Y. J. (2013). Optimization of cdt-1 and xyl1 expression for balanced coproduction of ethanol and xylitol from cellobiose and xylose by engineered Saccharomyces cerevisiae. PLoS ONE 8:e68317. doi: 10.1371/journal.pone.00 68317

Zha, J., Shen, M., Hu, M., Song, H., and Yuan, Y. (2014). Enhanced expression of genes involved in initial xylose metabolism and the oxidative pentose phosphate pathway in the improved xyloseutilizing Saccharomyces cerevisiae through evolutionary engineering. J. Ind. Microbiol. Biotechnol. 41, 27-39. doi: 10.1007/s10295-0131350-y

Zhou, H., Cheng, J. S., Wang, B. L., Fink, G. R., and Stephanopoulos, G. (2012). Xylose isomerase overexpression along with engineering of the pentose phosphate pathway and evolutionary engineering enable rapid xylose utilization and ethanol production by Saccharomyces cerevisiae. Metab. Eng. 14 611-622. doi: 10.1016/j.ymben.2012.07.011

Zhu, J. Q., Qin, L., Li, W. C., Zhang, J., Bao, J., Huang, Y. D., et al. (2015). Simultaneous saccharification and co-fermentation of dry diluted acid pretreated corn stover at high dry matter loading: overcoming the inhibitors by non-tolerant yeast. Bioresour. Technol. 198, 39-46. doi: 10.1016/j.biortech.2015.08.140

Conflict of Interest Statement: The authors declare that the research was conducted in the absence of any commercial or financial relationships that could be construed as a potential conflict of interest.

Copyright (C) 2015 Qi, Zha, Liu, Zhang, Li and Yuan. This is an open-access article distributed under the terms of the Creative Commons Attribution License (CC BY). The use, distribution or reproduction in other forums is permitted, provided the original author(s) or licensor are credited and that the original publication in this journal is cited, in accordance with accepted academic practice. No use, distribution or reproduction is permitted which does not comply with these terms. 